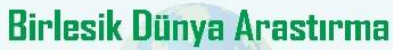 BD-CENTER World Journal on Educational Technology: Current Issues
}

\section{Dashboard proposal implemented according to an analysis developed on the KNIME platform}

Jhon Edwar Ninasivincha-Apfata a , Faculty of Education Sciences, Universidad Nacional de San Agustín de Arequipa, Perú; https://orcid.org/0000-0002-5026-9740

Ricardo Carlos Quispe-Figueroa b ${ }^{b}$, Faculty of Education Sciences, Universidad Nacional de San Agustín de Arequipa, Perú; https://orcid.org/0000-0002-1877-8131

Manuel Alejandro Valderrama-Solis ${ }^{c}$, Professional School of Telecommunications Engineering, Universidad Nacional de San Agustín de Arequipa, Perú; https://orcid.org/0000-0003-2587-8541

Benjamin Maraza-Quispe *d, Faculty of Education Sciences, Universidad Nacional de San Agustín de Arequipa, Perú; https://orcid.org/0000-0001-8845-4979

\section{Suggested Citation:}

Ninasivincha-Apfata, J.E., Quispe-Figueroa, R.C., Valderrama-Solis, M.A. \& Maraza-Quispe, B.M. (2021). Dashboard proposal implemented according to an analysis developed on the KNIME platform. World Journal on Educational Technology: Current Issues. 13(4), 816-837. https://doi.org/10.18844/wjet.v13i4.6267

Received from; July 11,2021 revised from; August 23,2021, accepted from; October 19,2021

Selection and peer review under responsibility of Prof. Dr. Servet Bayram, Yeditepe University, Turkey.

(C2021 Birlesik Dunya Yenilik Arastirma ve Yayincilik Merkezi. All rights reserved.

\begin{abstract}
The objective of the research is to develop a methodology to analyse a set of data extracted from a learning management system, in order to implement a dashboard, which can be used by teachers to make timely and relevant decisions to improve the teaching-learning processes. The methodology used consisted of analysing 9,257 records extracted through simple random sampling from a population of 100,000 records. The indicators analysed were number of accesses, course grades, time spent, number of courses enrolled and number of activities developed. The results show that the data analysis was carried out on the (o Konstanz Information Miner (KNIME) data mining analysis platform, and the model was implemented in five phases: requirements definition, model design, development, implementation and evaluation of results. The results are taken as a recommendation to design and implement a customised dashboard for teachers to identify observable behavioural patterns that allow them to make decisions to improve the teaching-learning processes of students.
\end{abstract}

Keywords: Analytics, dashboard, KNIME Learning, personalised, teaching

* ADDRESS FOR CORRESPONDENCE: Benjamin Maraza-Quispe *d, Faculty of Education Sciences, Universidad Nacional de San Agustín de Arequipa, Perú

Email Address: bmaraza@unsa.edu.pe 


\section{Introduction}

The use of technology in the remote work of teachers and the use of better tools that facilitate the teaching-learning process and the evaluation of students in real time have increased in recent years. Education has evolved through the immersion information and communication technologies (ICT) in the teaching and learning processes. By becoming more ubiquitous and active (Ribeiro \& Montanaro, 2017), the transition to online learning has been difficult, yet it is expanding rapidly (O'Doherty et al., 2018). Given this situation, there is a predominance of virtual learning environments. Due to the increase in distance learning in recent years, there has also been a proportional increase in educational big data due to the large amount of data generated by the interactions that platforms allow (Asadi et al., 2019; Arriaran Olalde \& Ipina Larrannaga, 2019).

There is a need to monitor the current status of the academic performance of students by teachers in distance teaching-learning in virtual learning environments. Updated training in the use of technology for distance learning is also required (Michaeli et al., 2020). Distance learning, in the sense, is that generally the learning activities of a study programme do not require the physical presence of the student (Mahou-Lago et al., 2020). Given this trend of distance education and the need to analyse through data generated by the interaction of educational actors, this process is called learning analytics. These analytics are intuitive graphical representations about the activity and performance of the students, in order to optimise it (Mejia et al., 2017). The main objective is to provide processed information on the real situation, through data collection, in such a way to anticipate and improve student performance (Hibbi et al., 2019) as an emerging field; it has been shown that it contributes to the prevention of dropout, as well as the optimisation of the teaching-learning process.

\section{Conceptual or theoretical framework}

Given the problems caused by the health crisis generated by the COVID-19 pandemic (Marek et al., 2021; Sharma \& Bumb, 2021), there is a need for the correct use of virtual learning environments by teachers. It is necessary to design a detailed report viewer that allows showing student performance data that allow timely decision-making. As mentioned by Ordonez-almeida et al. (2020), there is a permanent need to train educational actors in the Moodle platform because there are shortcomings identified in the training of the pedagogical application of the tools. Its main use is usually as a job manager (Del Prete et al., 2018). In conclusion, there is evidence of the lack of training of teachers regarding the proper use of the platform, as well as problems in the methodology, content management and evaluation. Therefore, it is necessary to find a way to support the solution of this problem. It is essential to carry out this type of research in conditions where, for the first time, full use of teaching is made through the Moodle platform.

Learning management systems (LMSs) are implemented in order to improve educational quality, but the analysis of the impact on learning is still a subject of recent research (Arriaran Olalde \& Ipina Larrannaga, 2019; Mwalumbwe \& Mtebe, 2017). Moodle is a platform that has become very popular (Alexandre Scherbyna, 2020), but problems have also arisen due to the lack of knowledge of all its tools and in the correct use of these (Ribeiro \& Montanaro, 2017); for example, one of the reasons is that some of its functionalities are poorly known (Esnaola-Arribillaga \& Bezanilla, 2020). The use of 
virtual learning environments has become a constant need; therefore, it must be part of the skills of the 21st-century teacher.

Another problem in distance education is related to the interaction and communication between teacher and student. Since observing the behaviour of students, regarding their complex learning, it has been identified that monitoring the activities that are carried out by means of the Moodle report registry presents difficulty in use (Santoso et al., 2018). Therefore, behaviour is partially observable, but with data analysis techniques, significant information can be extracted to serve as data for a more complete and detailed observation.

\section{Related research}

Learning analytics is completely related to educational technology. This is because it has an impact when it comes to displaying information related to students and the online teaching-learning environment (Kew \& Tasir, 2021). KNIME is a software that provides a platform where new functions and tools can be easily used; it has a data system that records the steps of the workflow in detail (Fillbrunn et al., 2017). It also provides a visual graphical user interface for designing and debugging the data analysis process (J. Jara et al., 2014). The best way to view learning analytics in the education community is the dashboard, which helps provide solutions in learning analytics for administrators, teachers and students to use (Kew \& Tasir, 2021). By using data visualisations as scaffolding tasks, the results of the study demonstrate the proposed model as a teaching tool in the project-based education. The findings of the paper show that the developed model provides students with the opportunity to develop accounting analytics visualisation skills and increase students' engagement by exposing them to real-world projects in the accounting domain (Prokofieva, 2021).

As Saiz-Manzanares et al. (2020) mentioned, it is necessary to design complements to optimise the different aspects of monitoring to implement them in the LMS because they have a monitoring system that calculates simple metrics. The data generated by the interaction is difficult to analyse to predict the performance from Moodle (Liu et al., 2019). Moodle has limitations due to the lack of tools to monitor students in real time because personalised data processing is more expensive, but it can be complemented with plugins or systems that demonstrate a solution in the efficiency of processing personalised queries (Zacarias et al., 2016). It also has a very complex and inflexible internal structure, which makes it difficult to modify. An alternative is to use it to collect data for the purpose of further analysis in another system (Dominguez et al., 2016). Similarly, our Moodle-based LMS has a very simple and non-interactive monitoring reporting function for the visualisation of relevant data that contributes to timely decision-making in teaching. Some virtual learning environments provide reports and logs so that teachers can track student performance, but they have a deficiency in facilitating learning analysis and are not intuitive (Brito et al., 2019) or inappropriate to use (Michaeli et al., 2020). According to Tlili et al. (2018), in distributed teaching, it is more difficult to monitor, control and adjust the learning process. The data generated is crucial to analyse and generate knowledge for decision-making. For this reason, early identification of students who need support is possible through data captured by a system (Liu et al., 2015). In this sense, various external tools have emerged, such as control panels or dashboards, which serve to facilitate the visualisation and monitoring of activities and provide information in real time by connecting an API (Zimmerman et al., 2016). 
According to Brito et al. (2019), the learning analytics risk report plugins use data visualisation techniques to show the cognitive, social and behavioural indicators of learning. It also provides mechanisms that promote the improvement of student performance, mainly from those at risk of dropping out, based on access, interactions (in the forum) and performance indicators (less than 50\%), as it is a qualitative research. As a result, the plugins allow the teacher to intervene and rescue students who have never accessed the platform and those who have low performance, as well as some limitations in the export and filter of reports.

Saiz-Manzanares et al. (2020), in the proposal of an eOrientation plugins, designed, developed and implemented the Moodle platform that graphically analyses the record of interactions of students and teachers, such as the frequency of access and participation, through an information extraction process. In addition, its effectiveness was proven, facilitating the monitoring of students and the detection of academic dropouts using predictive machine learning techniques. It was studied whether the type of grade variable predicted the students' learning behaviours and it was found that the variable with the highest predictive value between the two groups of grade students was the frequency of access to exams. The grouping technique was also applied, and three groupings were found for the distribution of the frequency of student access to the platform's resources. In addition, data visualisation tools based on the orange software were used, specifically prediction and classification aspects were shown. Similarly, Santoso et al. (2018) developed the data visualisation dashboard as a supporting tool for teachers and for monitoring learning, which guides the teacher and adjusts to the needs that can be improved after obtaining the information of the students. Principles such as visualisation are also applied, which would be the attributes of creativity and visual perception for the organisation of the visual components in the dashboard where in the qualitative evaluation its usefulness of the prototype was satisfactory. In turn, Tlili et al. (2018) indicate that Imoodle is a system integrated by Moodle, which presents a dashboard in an integrated system, in order to collect and extract meaningful information from the database where teachers can track their students, in order to control the online learning process, proposing a future study on the evaluation of efficiency. Similarly, Florian-Gaviria et al. (2013) mentioned that the SOLAR application provides learning analysis on the development of capacities with different social perspectives parallel to the social plane. For the support to the follow-up, they received high satisfaction where $80 \%$ of the teachers were able to identify patterns of failure. SOLAR can help teachers to raise awareness, stimulate reflection and understand the behaviour of students on a social level. While EMODA (EzZaouia \& Lavoue, 2017) is an emotional board that displays emotional data on a videoconferencing platform and focuses on synchronous interactions through the application of both dimensional and discrete emotional models. We demonstrate that the emotions of different students can be detected during these environments. In the initial study of the EMODA board, to obtain the perception of the usability of the board, the tutors confirmed that the board is easy to use. This suggests that a simplified display would be easier to understand. Also, LEARNATO (Van Alphen \& Bakker, 2016) is a dashboard that provides teachers with progress information in real time. Participants reported using the board time efficiently. Only the information extraction process was a slow task, but in general they indicated that they feel supported by the information they obtain on the board for a differentiated instruction.

The dashboards integrated in the LMS that had good results mostly indicate that they arise due to the difficulties. Similarly, SoftLearn Activity Reporter (SLAR), described by Ramos-Soto et al. (2015), is integrated into the Soft Learn platform to complement the information provided by its graphical 
visualisation tools with the textual reports of the data displayed, helping teachers understand student behaviour during the course. Furthermore, SLAR's performance in terms of content veracity meets expectations to a high degree.

Purpose of the study

The results of the developed analysis are taken as recommendations to design and implement the proposed personalised dashboard for teachers to identify observable patterns of student behaviour in a way that allows them to make timely and relevant decisions to improve the teaching-learning processes. In conclusion, a personalised dashboard is implemented according to the recommendations of the model implemented in the KNIME platform and can be generalised to other educational contexts.

The aforementioned research shows us that the dashboards focus on some indicators for better visualisation and help the work of teachers in the distance teaching-learning process. On the other hand, our proposal includes optimal indicators obtained by a rigorous process of cataloguing the appropriate indicators so that they can be visualised in the dashboard design and that they have a better impact on the context. In fact, the current architecture should be modified to offer real-time visualisation to teachers in order to optimise monitoring and make it more enjoyable. In addition, these tools need to be based on standards that the educator must have as indicated by the International Society for Technology in Education (ISTE) (Michaeli et al., 2021). The standards are as follows:

- $\quad$ Apprentice: Teachers follow a constant process of learning from their practice exploring successful practices that use technology to improve student teaching-learning.

- $\quad$ Leader: Teachers seek opportunities to actively promote student learning and their own teaching.

- $\quad$ Citizen: Teachers encourage students to make positive contributions to the digital world and participate responsibly.

- $\quad$ Collaborative: Teachers spend their time collaborating with their colleagues and students to improve their practice.

- $\quad$ Designer: Teachers design authentic student-oriented learning activities and their variables.

- $\quad$ Facilitator: Teachers use technology to promote learning and support student achievement.

- $\quad$ Analyst: Teachers understand data to improve teaching and promote student learning.

The research question that we posed is: To what extent will the design of a dashboard based on a personalised model help efficient visualisation for the best timely decision-making of teachers in the virtual learning environments? 


\section{Method and materials}

The methodology used consisted of analysing 9,257 records extracted from the LMS; these data only constitute the sample of a total of more than 100,000 records. The indicators analysed were number of accesses, course grades, time spent, number of courses enrolled and number of activities developed. The data analysis was developed in the data mining analysis platform KNIME. The analysis model was implemented through the following phases: requirements definition, model design, development, implementation and evaluation of results.

\section{Below are the objectives to be analysed in the KNIME platform according to the data set that was extracted.}

\subsection{Research model}

The research used a quantitative approach where the objectives to be analysed in the KNIME platform are as follows:

- Identify observable behaviour patterns through the relationship between the time spent in the courses and the time dedicated to the development of activities.

- Identify indicators of academic performance towards the achievement of success and low performance through the relationship between the activities completed and their qualification.

- Identify the effectiveness of the activities through the relationship between activities completed, tasks performed and the average obtained in the course.

- Track student activities and interactions through the relationship between time spent in a course and average grade received.

- Compare the development of the activities with the other students through the relationship between the time dedicated to the courses and the time dedicated to the activities.

\subsection{Participants}

For the implementation of the dashboard proposal, the LMS data was analysed through a model implemented in the data mining platform KNIME (Kresimir et al., 2014). Online behaviour indicators were extracted, such as access, rating and time, from the website and valid information from the LMS of the Faculty of Education of the Universidad Nacional de San Agustin.

The data from the 9,250 record samples used were extracted through simple random sampling of a total population of 100,000 records of the faculty LMS, using the IntelliBoard tool. With this data set, the model was implemented in the KNIME platform whose recommendations of the analysis carried out allowed implementing the proposed customised dashboard. The methodology for dashboard design (Robalino, 2017) consists of five phases: requirements definition, design, development, implementation and evaluation of the results. 


\subsection{Data collection tools}

\subsubsection{Phase 1: Definition of requirements}

Data records were extracted from the LMS using the IntelliBoard tool; data are related to the objectives for the analysis to be carried out through the model implemented in the KNIME platform. With these data, the dimensions and indicators to be modelled in the KNIME platform were proposed, as shown in Table 1.

Table 1. Indicators and dimensions of academic performance

\begin{tabular}{lc}
\hline \multicolumn{1}{c}{ Dimensions } & \multicolumn{1}{c}{ Indicators } \\
Access & Visits to courses clicks \\
Qualification & $\begin{array}{c}\text { Average rate } \\
\text { Grade by course }\end{array}$ \\
Weather & $\begin{array}{c}\text { Time for each course } \\
\text { Total time in courses } \\
\text { Total time in activities }\end{array}$ \\
Courses & $\begin{array}{c}\text { Enrolled courses } \\
\text { Activities seen } \\
\text { Homework }\end{array}$ \\
& Completed activities \\
\hline
\end{tabular}

\section{Data collection process}

\section{Phase 2: Design and modelling}

Data preparation was carried out using the reports extracted from the LMS in table format in spread sheets in files such as summary of activities on the site by user, site access statistics, demographic data, summary of activities carried out, student progress in the course etc.

We proceed to implement the nodes in the KNIME platform to process the data and achieve, as a result, a single table containing all the academic performance indicators.

As shown in Figure 1, the model was separated into two groups. In the first group, the data obtained from the reports extracted from IntelliBoard were processed. The second group of statistics corresponds to the modelling results according to the objectives requiring data visualisation. 


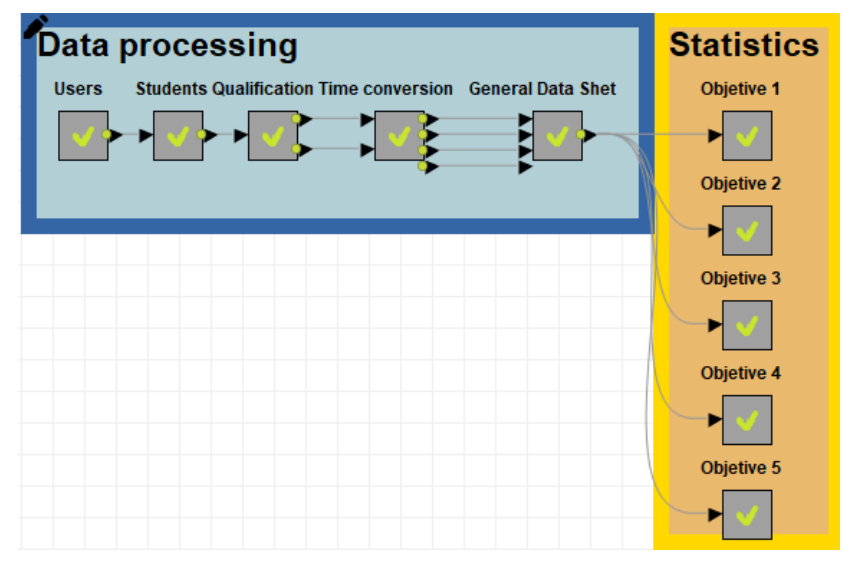

Figure 1. Logical representation of the modelling in KNIME

Figure 2 shows the methanode (union of nodes according to functionality) for all users where two reports are analysed: Summary of site activity by user and Access statistics. The Joiner node was used to join the tables containing data on accesses and qualifications, respectively, of 26,253 records.

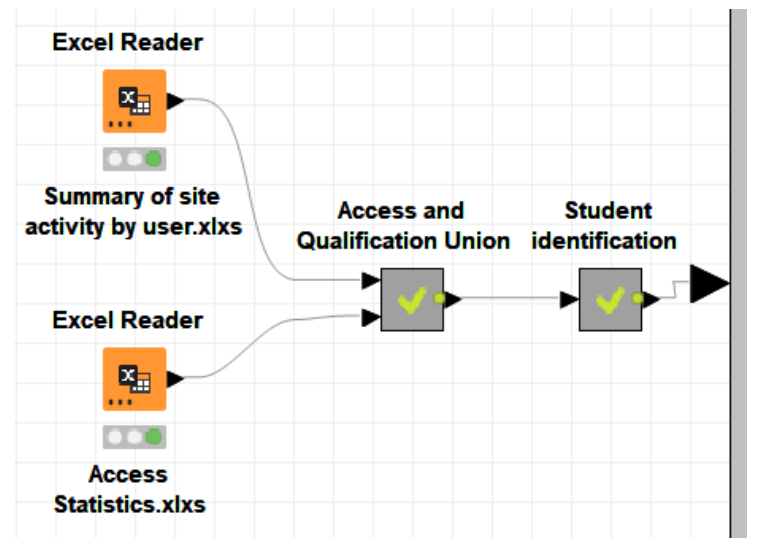

Figure 2. Methanode of all users

Figure 3 shows the Student Identification methanode where teachers and students are distinguished by joining with the Joiner node the Site Use by Instructor Summary tables and the table created in the previous methanode, Access and Qualification Union. 


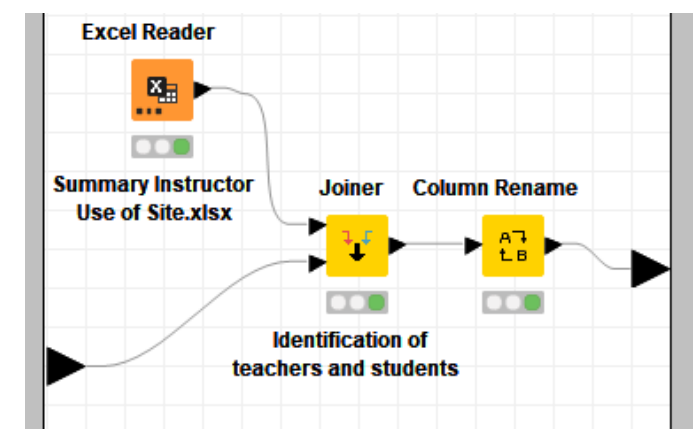

Figure 3. Student identification methanode

Figure 4 shows the methanode of students. With the Joiner node, we joined the Summary Instructor Use of Site tables and the previous Student Identification methanode table, filtering the student data from the teachers, resulting in 9,252 records.

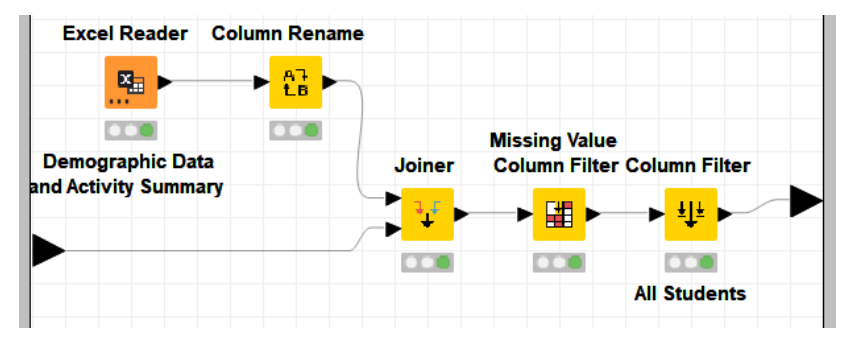

Figure 4. Students' methanode for filtering valid student data

Figure 5 shows the qualification methanode, which was used to verify the accuracy of the data extracted with IntelliBoard. With the GroupBy node, we averaged the course grades of each student, and then with the Joiner node we joined the two tables, adding a column to compare the average grade obtained by the GroupBy node with the IntelliBoard reports table.

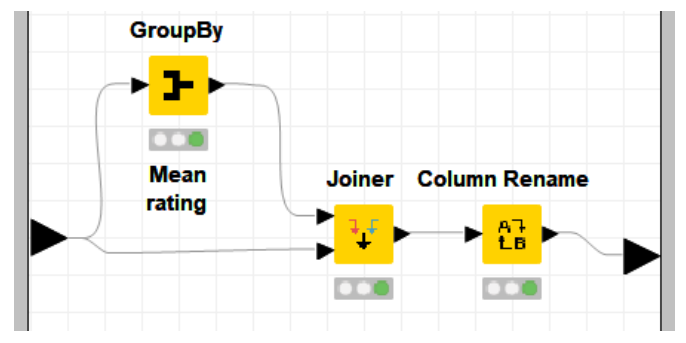

Figure 5. Methanode qualification for data validation

Figure 6 shows the time conversion methanode, the process of converting the time spent on courses and activities. It also includes a methanode on the reporting of course activities. 


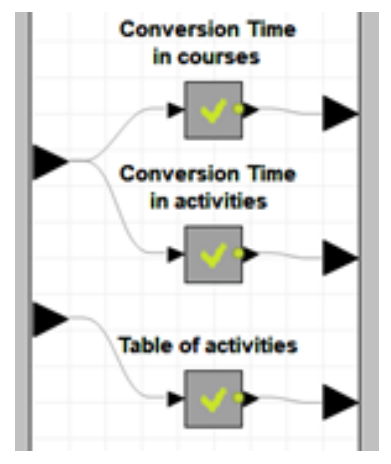

Figure 6. Time conversion methanode

\section{Data analysis}

Figure 7 shows the methanodes Conversion Time in courses and Conversion Time in activities, where the process of converting time into courses and activities is carried out. Due to the format of the time variable in hh:mm:ss in text string, with three String Manipulation nodes, the numbers of hours, minutes and seconds are extracted, generating new variables, respectively. By means of the String to number node, these variables are converted from text string to number. Then with the function of the Math Formula node, the previous variables of hours, minutes and seconds are joined in a single variable of time in seconds, and then another variable in hours is generated. Finally, with the Column Filter node, the necessary variables are kept, such as the variables of time in hours, TimelnCourseHrs and TimelnActivitiesHrs.

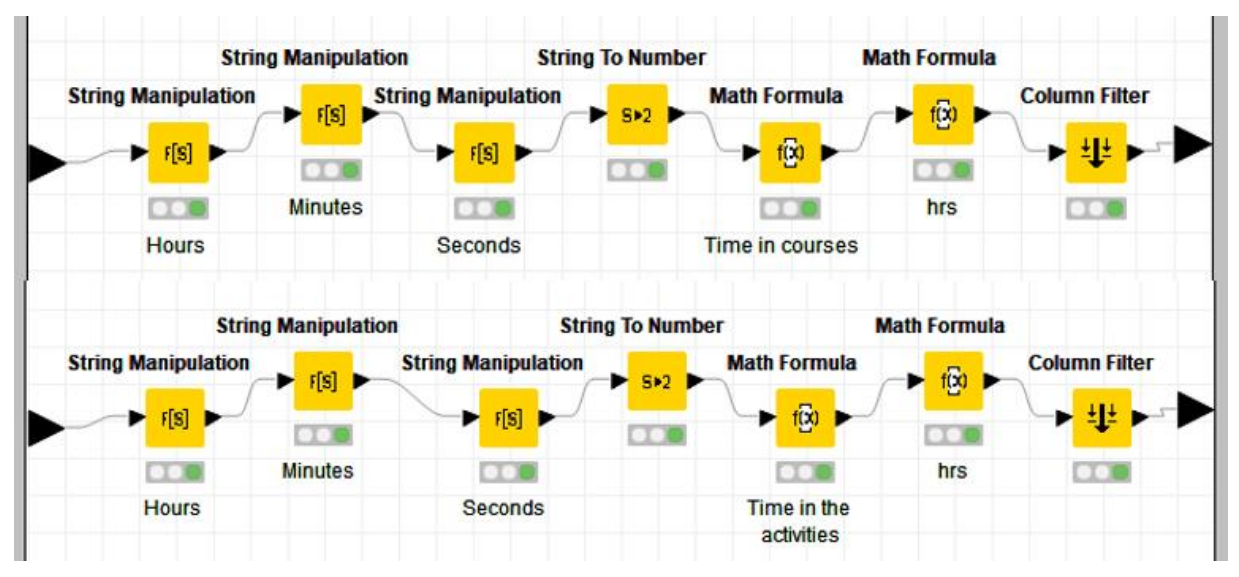

Figure 7. Conversion of time into courses and activities methanode

Figure 8 shows the table of activities methanode, where the progress course report is incorporated. The String to Number node is used to convert the number of completed activities, assignments and text assignments to number; then the GroupBy node is used to sum the number of activities viewed, completed activities and assignments of each course that the students have. The tables generated with the Joiner node are joined, creating the three summation variables. Finally, the necessary columns of the table are filtered with the Column Filter node. 


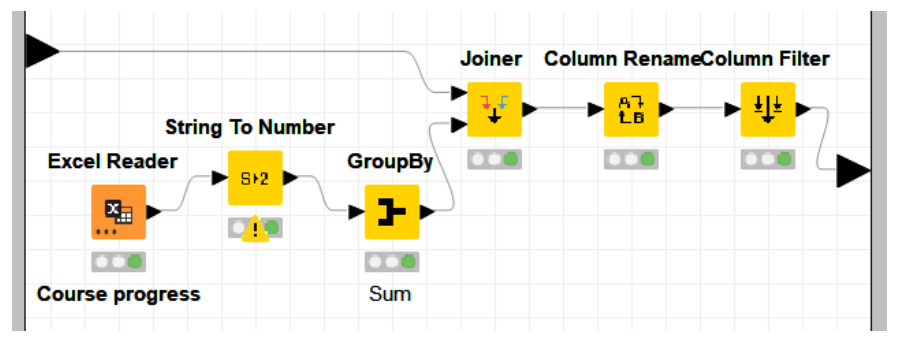

Figure 8. Methanode of the table of activities

Figure 9 shows the process methanode of the General Datasheet. It joins the different generated tables of time in the course, time in activities and the progress table of the course, by means of the Joiner nodes, based on the email, last name, first name and course fields, to generate a single table that contains all the necessary indicators for the proposed dashboard.

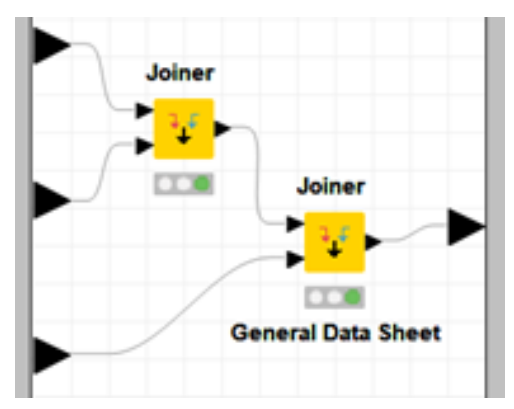

Figure 9. General datasheet methanode

Table 2 shows the parameters and descriptions involved in the data analysis, such as average grade, course enrolled, mail, time updated, time spent in the activities, number of tasks developed, number of activities completed and number of activities viewed. This data set was pre-processed through a previous analysis on the KNIME platform.

Table 2. Detailed description of the data

\begin{tabular}{|c|c|}
\hline Parameter & Description \\
\hline Average mark & Average score obtained from each student \\
\hline Course & Number of courses enrolled for each student \\
\hline Mail & Email to identify the number of students \\
\hline Current time & Time spent on average in all courses \\
\hline Time in activities & Average time spent on activities \\
\hline Homework & Total amount of homework for each student \\
\hline $\begin{array}{l}\text { Completed } \\
\text { activities }\end{array}$ & $\begin{array}{c}\text { Total number of activities completed for each } \\
\text { student }\end{array}$ \\
\hline Activities seen & $\begin{array}{c}\text { Total number of activities viewed by each } \\
\text { student }\end{array}$ \\
\hline
\end{tabular}

Figure 10 shows the processing methanode of the recommendation results for the first objective. The correlation was carried out using the Scatter Plot node that shows a scatter plot with the time in progress in hours, TimelnCourseHrs, as the independent variable and the time in activities in hours, TimelnActivitiesHrs, as the dependent variable. 


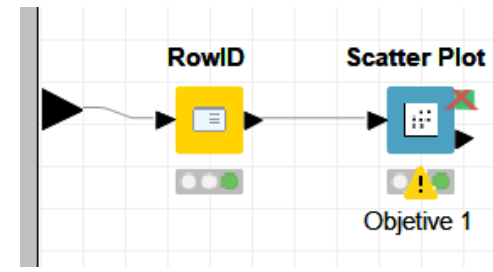

Figure 10. Recommendations to implement the dashboard for objective 1

Figure 11 shows the processing and recommendation methanode for the second objective. Using the Numeric Binner node in the rating variable, a distribution of the data in four nominal categories is configured: at the beginning from 0 to 50 points, in process from 51 to 70 points, expected achievement from 71 to 80 points and outstanding achievement from 81 to 100 points. Subsequently, the Colour Manager and Bar Chart nodes are used for the graphical visualisation of the average score variables and the number of activities carried out according to the categories.

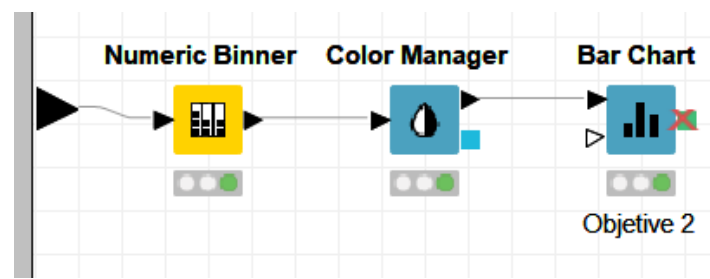

Figure 11. Recommendations to implement the dashboard for objective 2

Figure 12 shows the processing methanode to obtain the recommendations for the general dashboard for the third objective. The Colour Manager node was used for the number of activities variable, defining red as the minimum value and blue as the maximum value. Then, with the Scatter Plot node, a scatter plot was made and the number of activities was completed as the $X$-axis and the average rating as the $\mathrm{Y}$-axis.

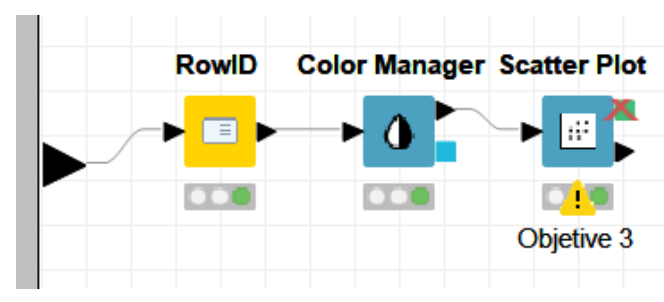

Figure 12. Recommendations to implement the dashboard for objective 3

Figure 13 shows the data processing methanode for the Dashboard implementation recommendation for the fourth objective. The String Manipulation node was used to extract the code representing an education specialty and create the code variable. With the Table Creator node, a data table was created with code and name fields for each of the nine education specialties. With the Joiner node, the table containing the code field was joined with the table containing the respective names of each specialty. The Rule Engine node was used to define custom rules to match some of the records it has with the exception's codes. Again, the resulting tables were joined with the Joiner node to include all the data. Finally, for the visualisation in graphs of the comparison of the variables of time in progress in hours and time in activities of each specialty of education, the Bar Chart node was used. 


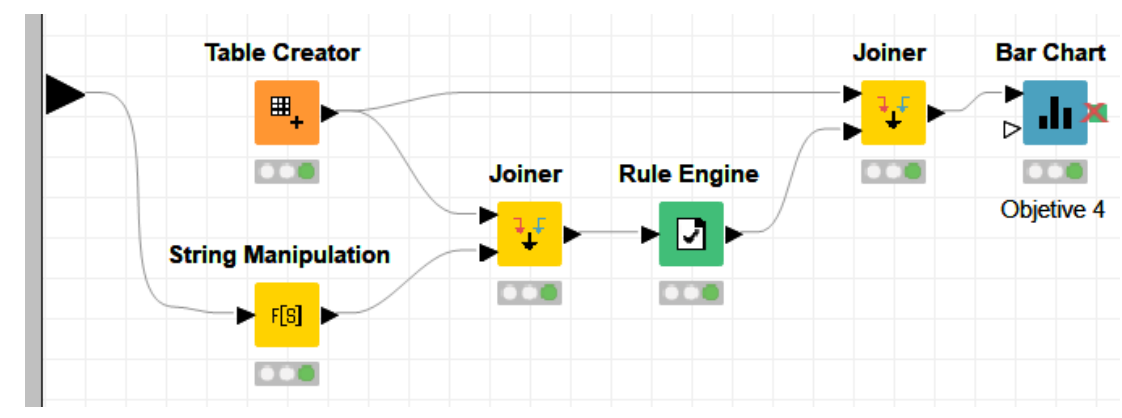

Figure 13. Recommendations to implement the dashboard for objective 4

Figure 14 shows the processing methanode and dashboard implementation recommendation for the fifth objective. The Scatter Plot node was configured for the scatter plot view with the variables TimelnCourseHrs and Average Rating.

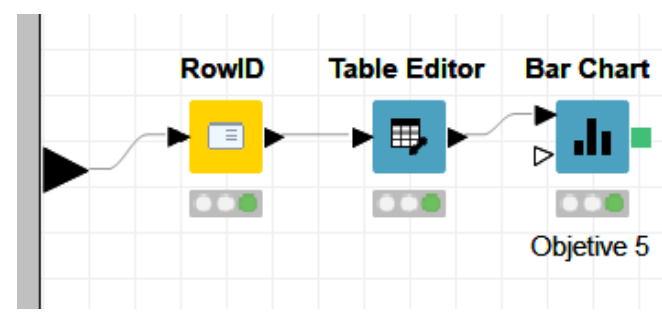

Figure 14. Recommendations to implement the dashboard for objective 5

\section{Results}

\section{Phase 3: Development and implementation}

Figure 15 shows the behavioural patterns observable through the relationship between time spent in the courses and time dedicated to the development of the activities.

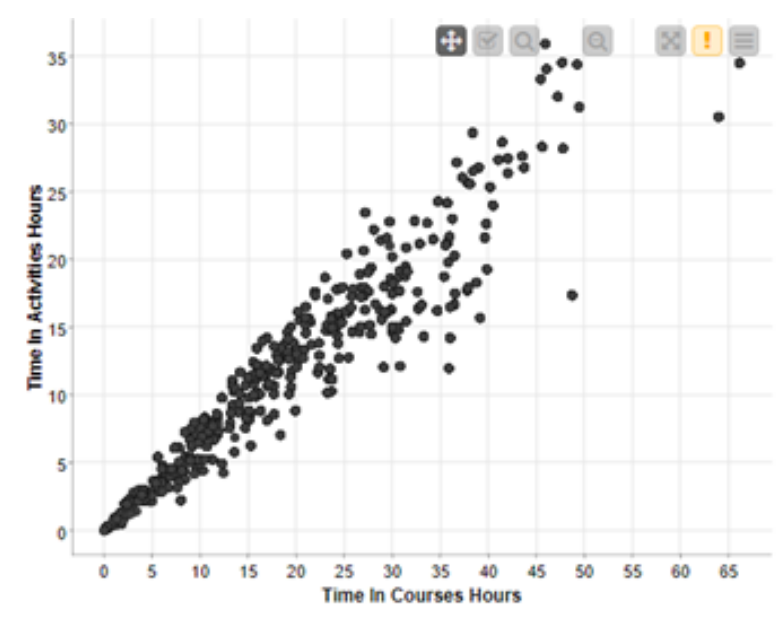

Figure 15. Relationship between time in courses and time in activities 
Figure 16 shows a higher frequency of students who are in the outstanding, expected and process levels, according to their academic performance. There are also many misleading values. Students who are going through the stages will have an increase in the number of activities until they reach the expected level, which does not vary in the number of activities completed.

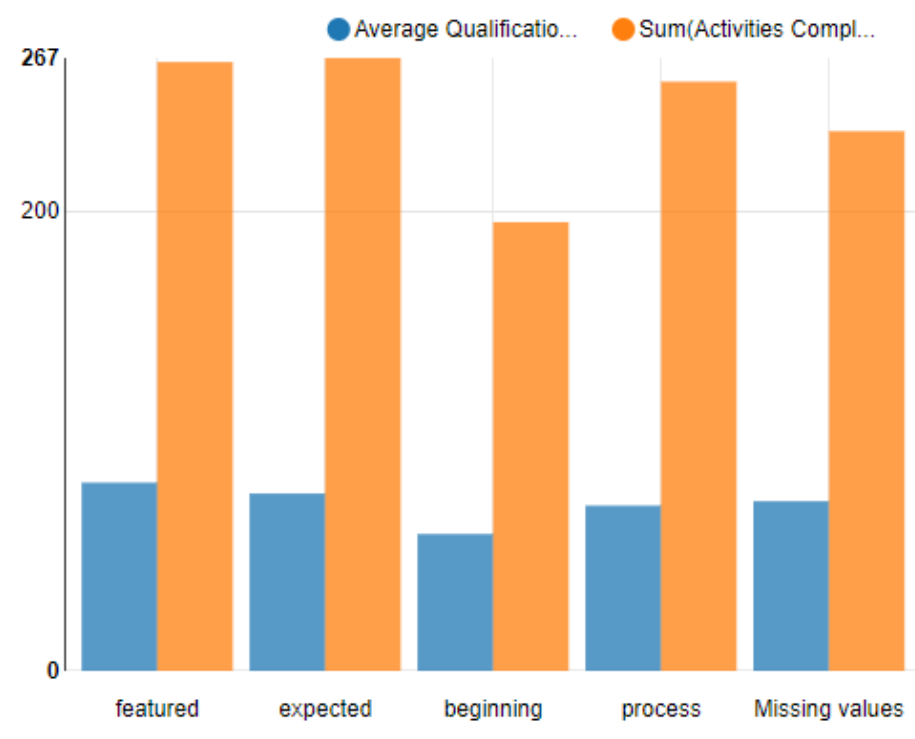

Figure 16. Relationship between completed activities and average grade

Figure 17 shows that most of the points are in the upper area, where it can be interpreted that a certain number of points are in the range of 0-200 activities completed with a score of 60-90.

Likewise, identification of the effectiveness of the activities, through the relationship between activities completed, tasks carried out and the average obtained in the course, was carried out.

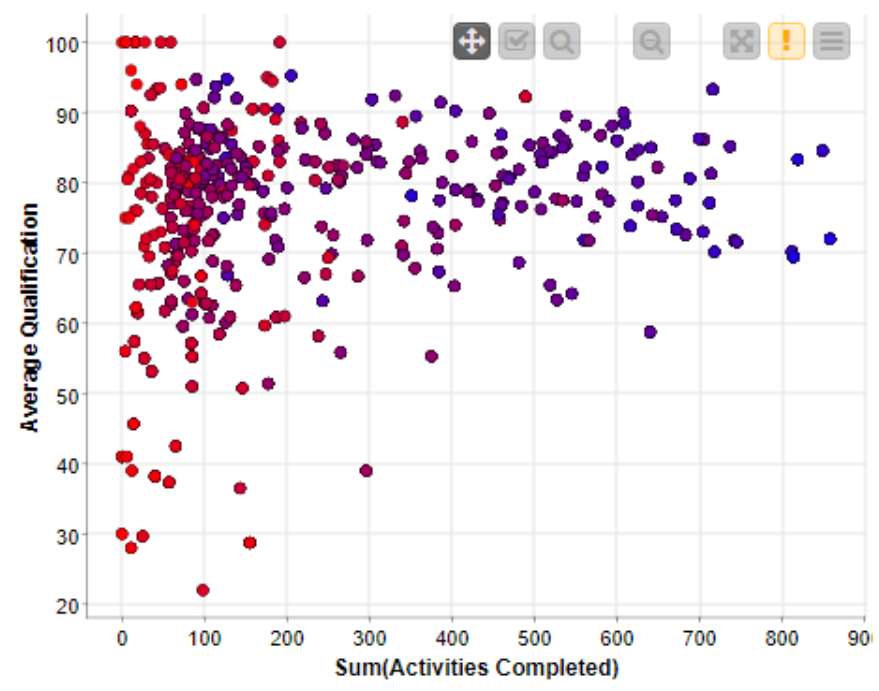

Figure 17. Relationship between completed activities, completed tasks and grade 
From Figure 18, it can be observed with respect to the subjects by major that the students dedicated more time to courses such as Natural Sciences; it can also be observed that there are more courses in the Natural Sciences major than in the other majors. An alternative explanation is that the activities in this major are more intense than the other majors.

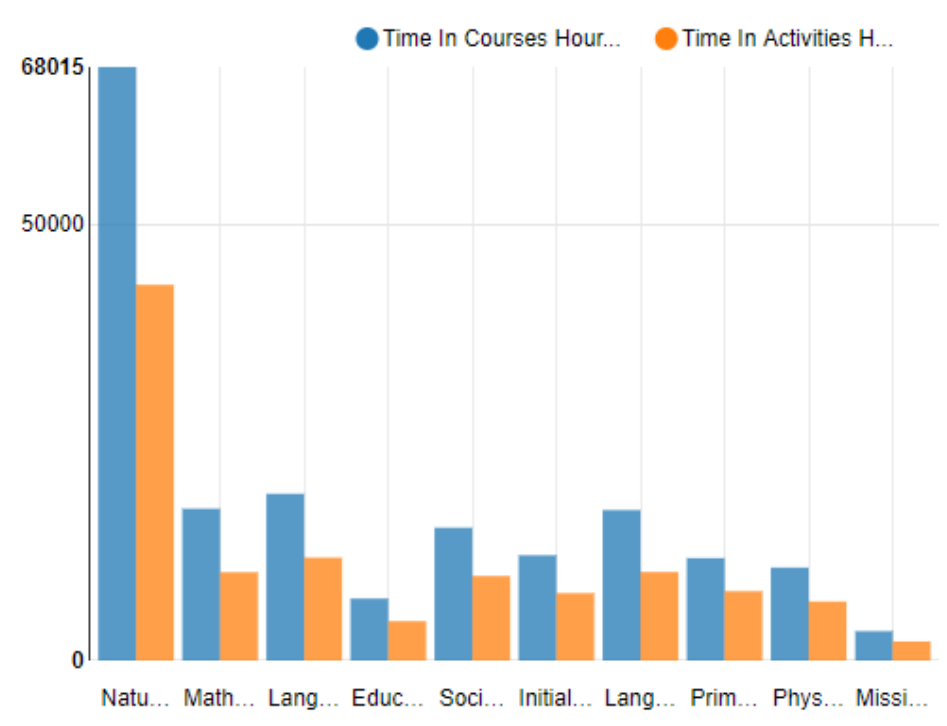

Figure 18. Ratio between time spent in courses and time spent in activities by specialty

Figure 19 shows that most of the points are in the upper part of the graph, where it is interpreted that a large number of students have a range of 0-35 hours per course and have a score ranging from 60 to 90 .

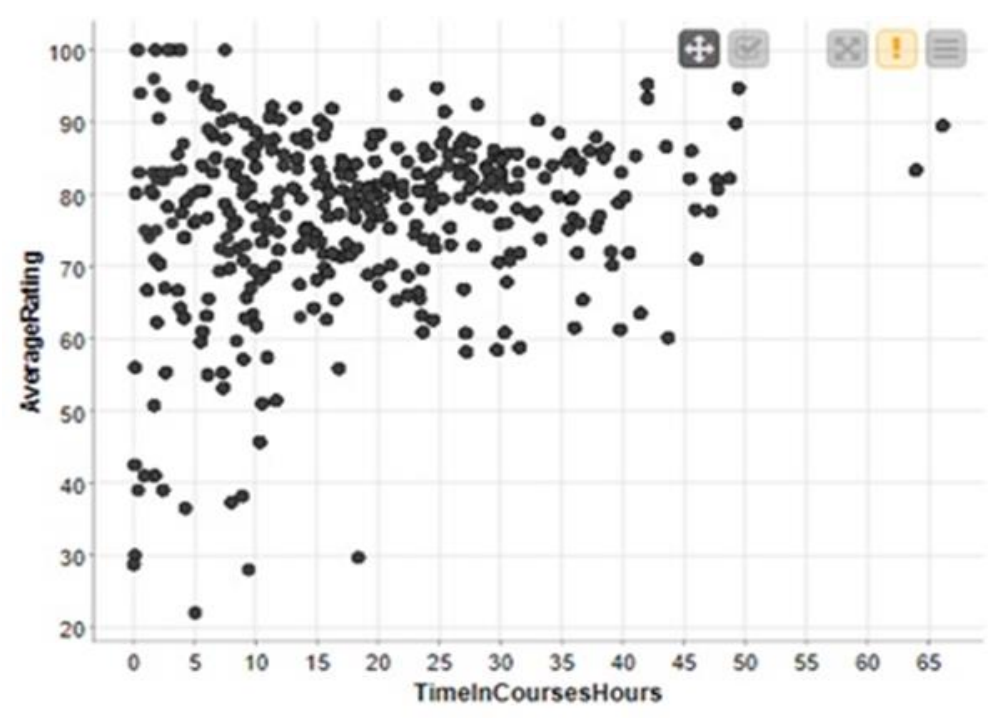

Figure 19. Relationship between time in courses and qualification 


\section{Phase 4: Implementation}

Figures 20-24 show the results of the proposed implementation. The visualiser shows that the proposed implementation objectives, whose data are displayed, were extracted from the KNIME model. The visualisation of the graphs and diagrams will help the teacher to make timely decisions to improve the teaching-learning processes, while at the same time monitor student performance to identify possible risks in academic performance. The dashboard link is http://dashboard.benjaminmaraza.com/index.php

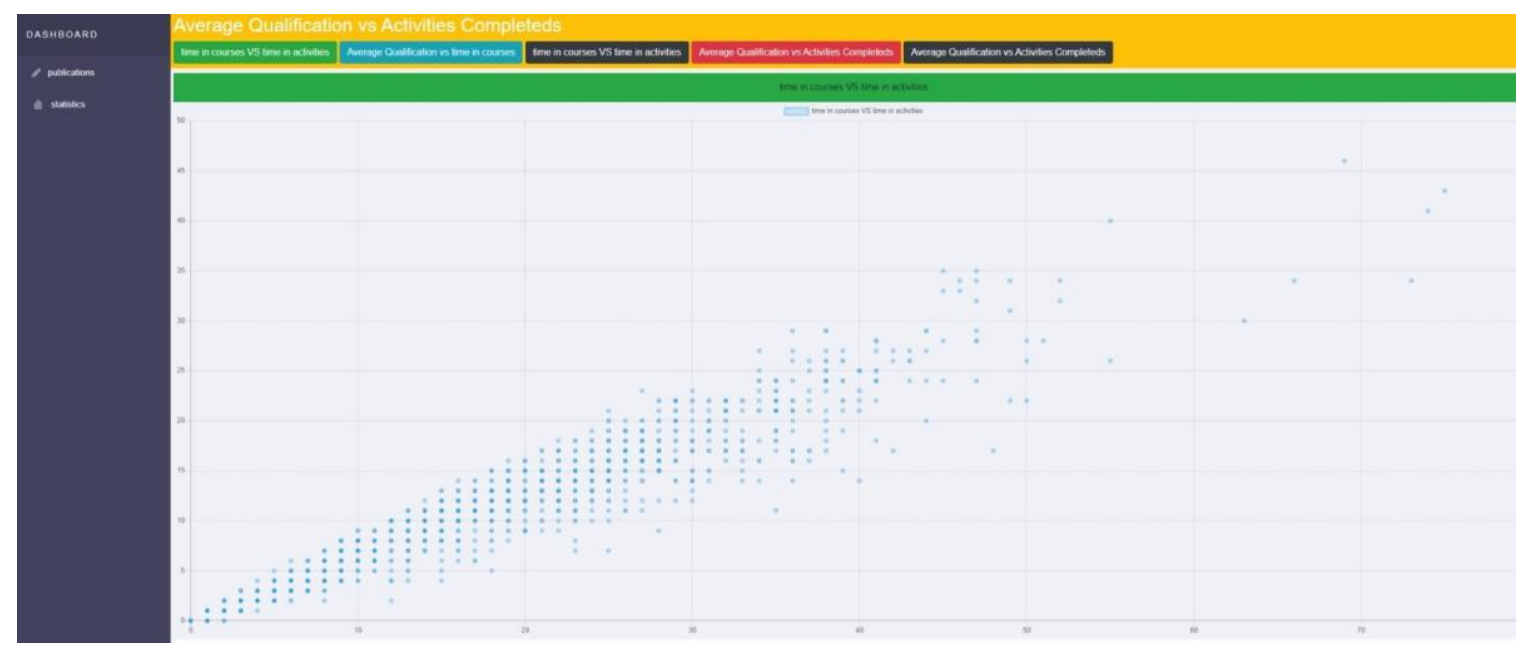

Figure 20. Course time versus activity time diagram

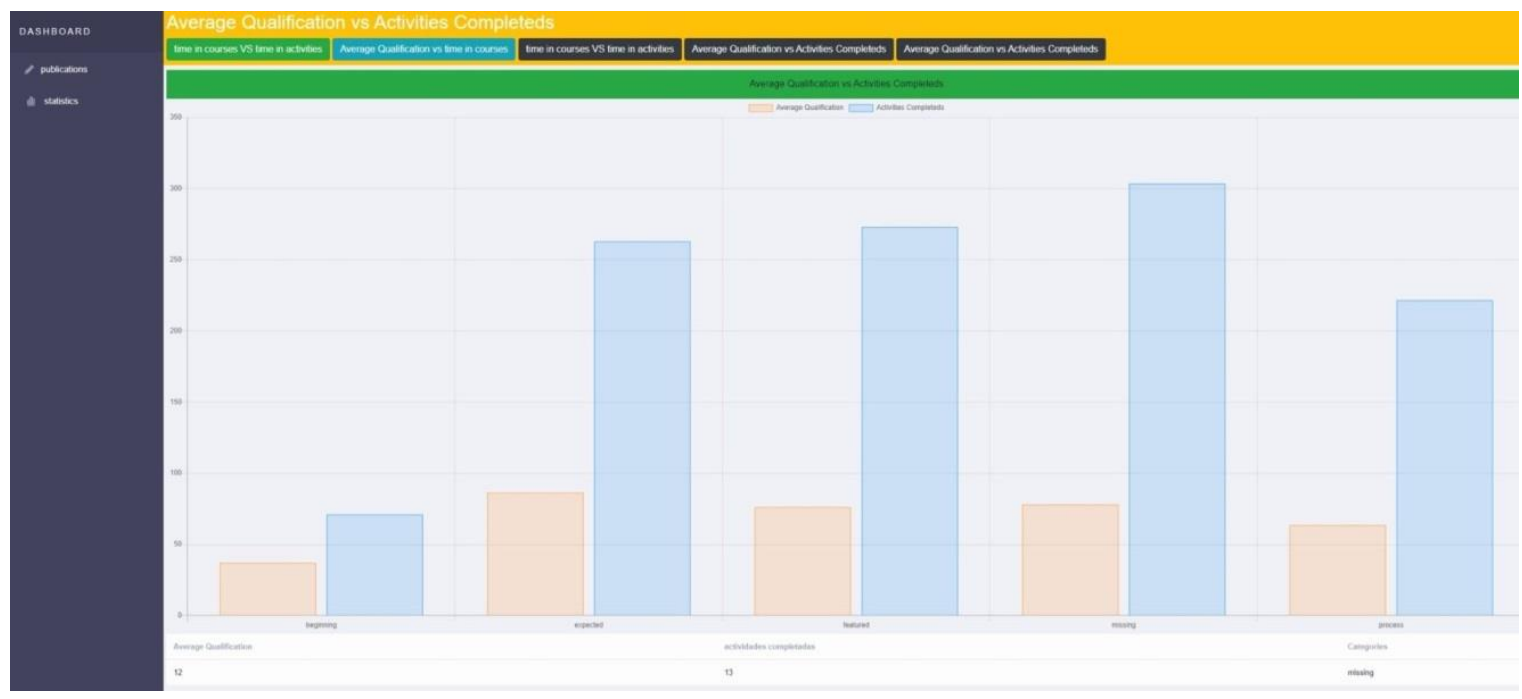

Figure 21. Graph of completed activities and average grade 
Ninasivincha-Apfata, J.E., Quispe-Figueroa, R.C., Valderrama-Solis, M.A. \& Maraza-Quispe, B.M. (2021). Dashboard proposal implemented according to an analysis developed on the KNIME platform. World Journal on Educational Technology: Current Issues. 13(4), 816-837. https://doi.org/10.18844/wjet.v13i4.6267

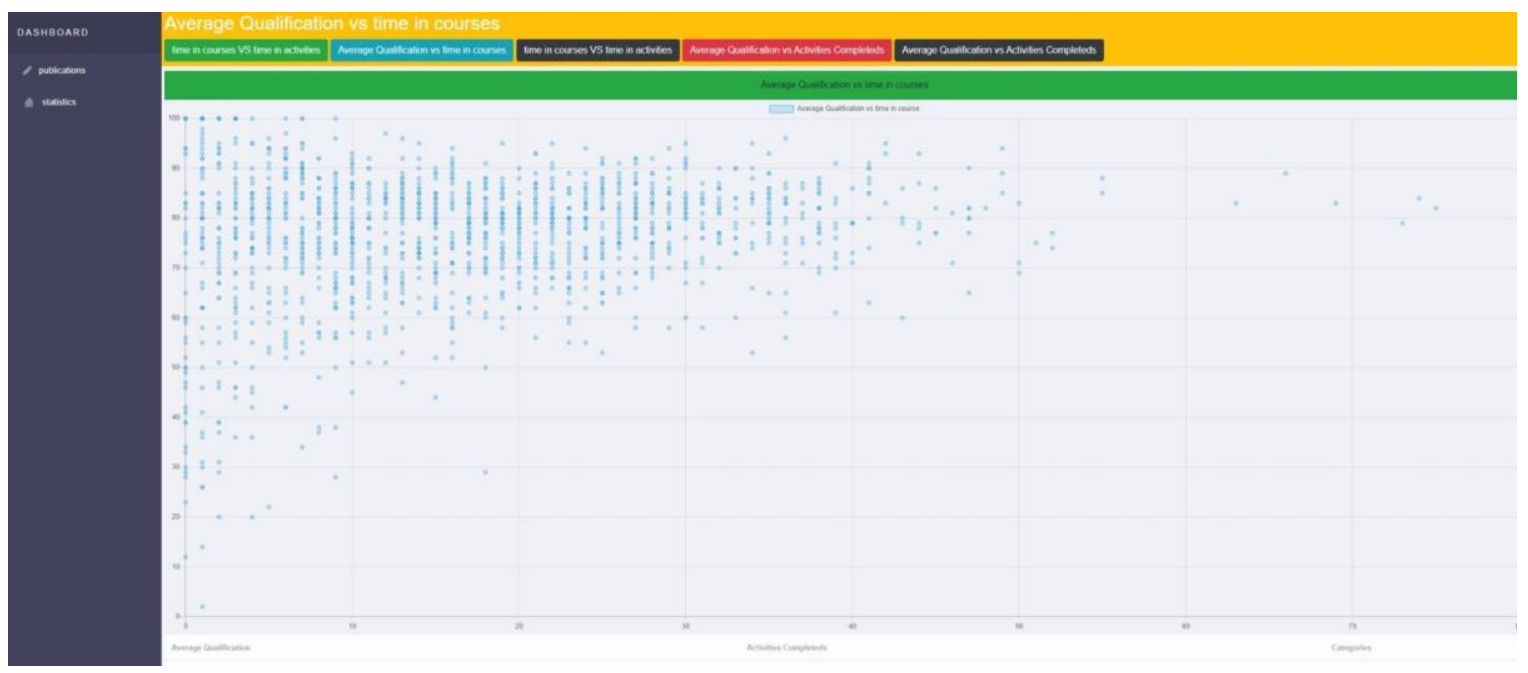

Figure 22. Diagram of completed activities versus qualification

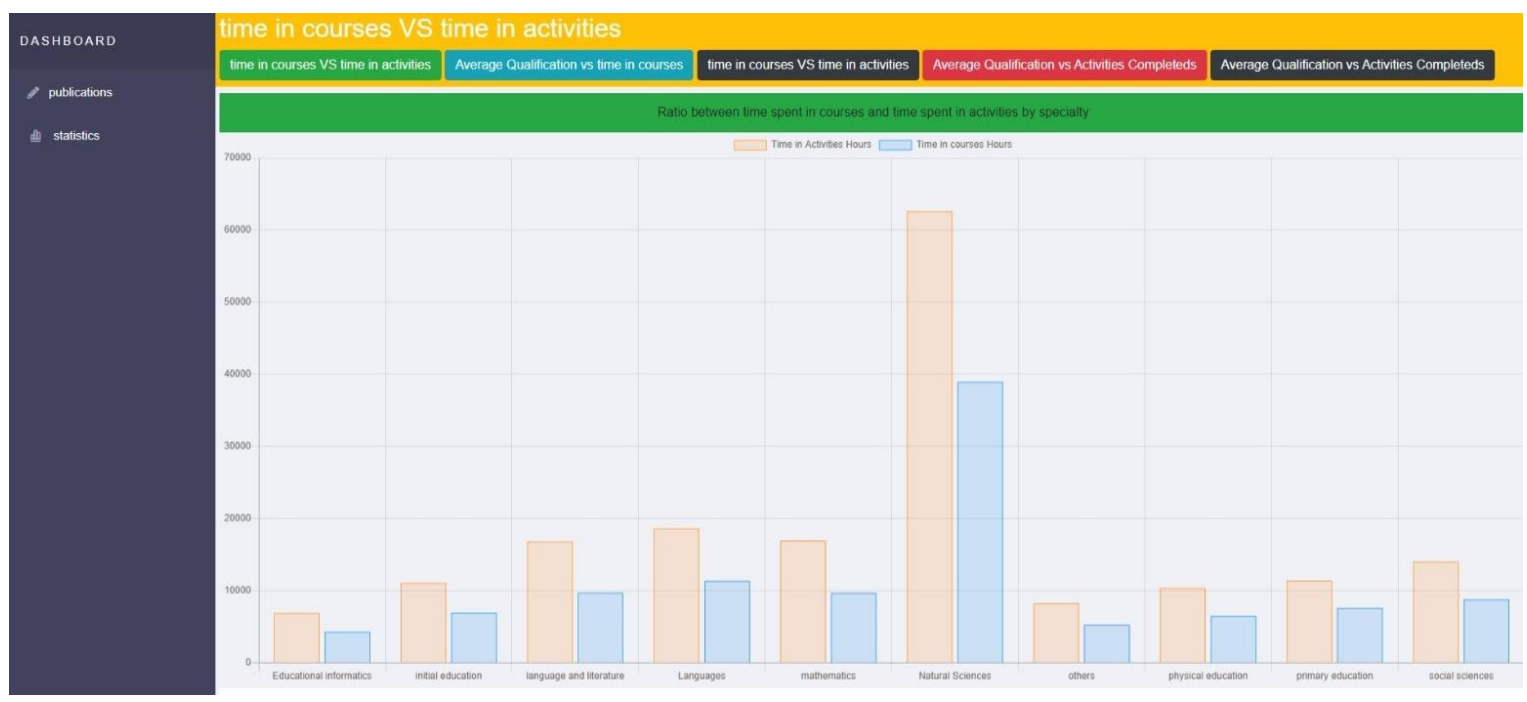

Figure 23. Graph of time in courses and time in activities by education specialty 


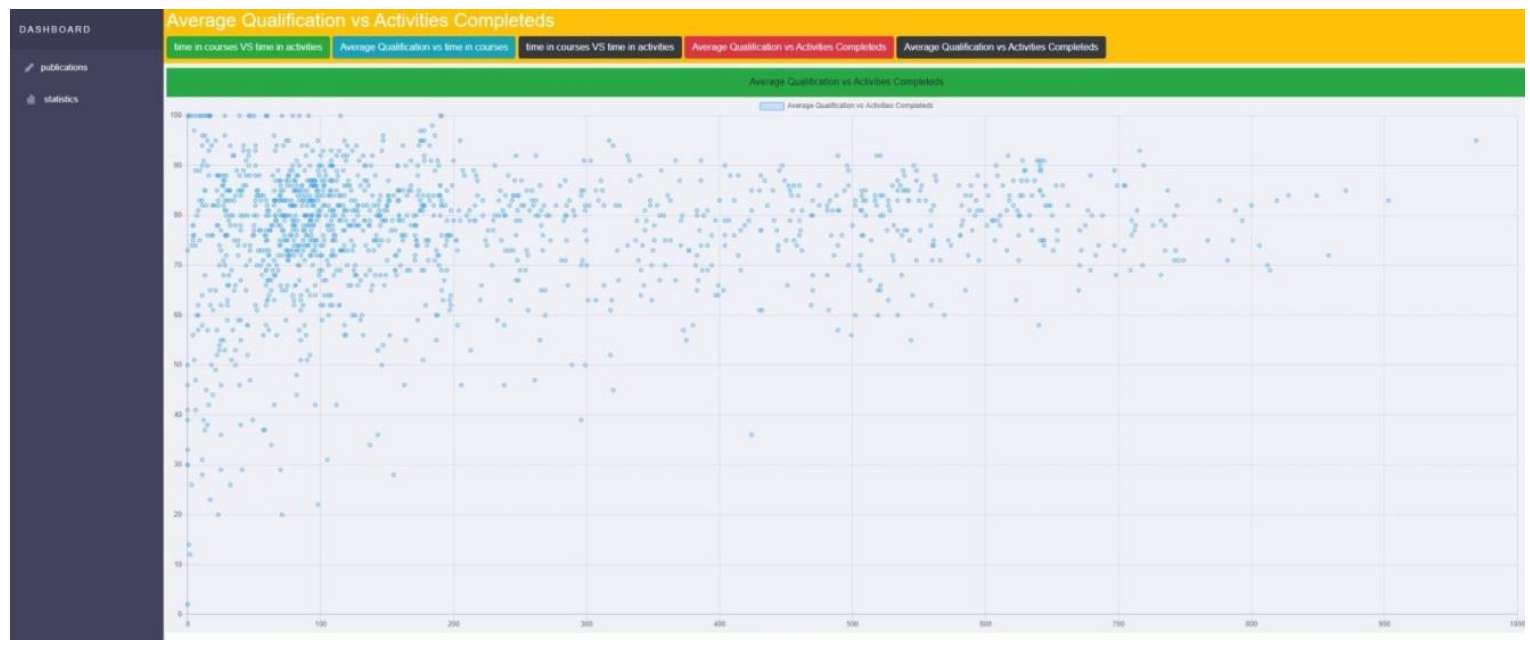

Figure 24. Course time versus grade point average diagram

The implementation was carried out according to the data analysis developed in the KNIME platform, whose recommendations are taken into account to implement the dashboard proposal, which are supported by the ISTE standards (Michaeli et al., 2020) in the part of the design and analysis that a teacher must carry out in teaching through ICT for the objective of designing a dashboard proposal that best suits the needs of the teacher and to optimise the teaching-learning process of students.

For better use and understanding of the analysis carried out on the KNIME platform, the distribution is carried out in a way to get the most out of it. The dashboard is composed of the options sidebar and at the top of the window and a navigation area for each of the graphs: Average Qualification vs time in courses, time in courses versus time in activities, average qualification versus activities completed and average qualification versus activities completed. The graphs and charts' display area is located in the central part of the window and a data report area is located at the bottom of the display area.

\section{Step 5: Evaluation of the results}

In the development of the work, the planning has been followed consistently, except for some specific moments in which the magnitude and the need for planning calculation were not enough to cover the whole picture of the objectives in the proposed planning. The KNIME modelling allowed testing different statistical graphs that were then implemented on a website.

To Society for carry out this evaluation, the International Technology in Education (ISTE) (Michaeli et al., 2020) standards of designer, facilitator and analyst were considered, as it allows teachers to design unique learning activities oriented to students, where technology is used to promote learning and support students' academic performance, and finally, where teachers can understand the data to improve teaching. Therefore, in the proposal of the control board to optimise the teacher's performance in the distance teaching-learning process, the analysis for each academic performance indicator was made for its visualisation in graphs, according to the objectives, in order to propose a useful tool for the teacher.

\section{Discussion}


Based on the findings, in the learning analytics risk report plugin research (Brito et al., 2019), where only indicators access to courses, forums and grades are considered to detect academic performance, and the research conducted by eOrientarion (Saiz-Manzanares et al., 2020), two indicators (frequency of access and participation) are used to detect dropout, which also allows graphical visualisation. Similarly, the research by Saiz-Manzanares (2020) shows the relevant information deals with course visits and the correlation principle to group the information and be visualised in graphs. In the research by Tlili (2018), their tool helped in monitoring the online learning process based on completed activities; the research by Florian-Gaviria (2013) shows in his dashboard the results of the activities, which can identify patterns of success or failure; moreover, the research of the LERNATO dashboard (Van Alphen \& Bakker, 2016) shows information about progress in real time through bar charts; finally, in the research of SLAR, the activity and inactivity indicators are analysed. Unlike the proposals of the mentioned researches, the dashboard, which was proposed in this research, is considered as a tool that can optimise the performance of the teacher in the teaching-learning process because the indicators are based on the access indicators, the time spent in the course, in activities, completed activities and grading, which can be visualised in bar charts and scatter plots the correlations of the indicators in the dashboard to optimise the monitoring of students in distance learning.

The dashboard proposal is based on ease of use and usability, as in the research on the EMODA (Tlili et al., 2018). As future work, it will be implemented in a real environment.

\section{Conclusion}

It has been possible to implement the proposal of a personalised dashboard according to the recommendations of the data analysis and processing implemented in the KNIME data mining platform from a set of data obtained from a learning management system, which can be replicated to other contexts.The results lead to different conclusions in the different figures resulting from the model applied in the research. Thus, defining a conclusion for each resulting graph was also possible to identify the most relevant and fundamental variables for the optimisation of the teacher's performance in the teaching-learning process.

Taking IntelliBoard as a tool, the indicators were selected from the extracted data, according to the greater usability of the activities on the platform. Finally, these actions were studied to expand the points of view assumed from the theoretical study and the experience of different authors to confront and adopt new ideas, which favours the consideration of other alternatives and criteria or indicators of behaviour in virtual learning environments.

The complementary tools for virtual learning environments are useful in the distance teachinglearning processes. This provides great help for learning to be more efficient in the virtual modality.

\section{Recommendations}

Despite the promising results of the proposed model for implementing a dashboard, there are certain limitations. In particular, no correlation analysis was conducted with the outcome of content assessment, e.g., quizzes, midterm and final exams. In fact, this was left for a future effort, as the focus here was to analyse a data set and generate a dashboard based on these.

\section{Acknowledgements}

This research was made possible with the support of the National University of San Agustin de Arequipa 
Ninasivincha-Apfata, J.E., Quispe-Figueroa, R.C., Valderrama-Solis, M.A. \& Maraza-Quispe, B.M. (2021). Dashboard proposal implemented according to an analysis developed on the KNIME platform. World Journal on Educational Technology: Current Issues. 13(4), 816-837. https://doi.org/10.18844/wjet.v13i4.6267

through UNSA INVESTIGA (Contract IBA-CS-07-2020-UNSA).

\section{References}

Alexandre Scherbyna (2020). Cmi5 - Новий Стандарт Інтеграції Засобів Для Електронного Навчання. Information Technologies and Learning Tools, 77(3), 355-368. https://doi.org/10.33407/itlt.v77i3.2989n

Arriaran Olalde, I., \& Ipina Larrannaga, N. (2019). Indicadores necesarios para disenar un dashboard desde la perspectiva de los profesores: un estudio cualitativo. Revista Iberoamericana de Educación, 80, 157-166. https://doi.org/10.35362/rie8013462n

Asadi, N., Khodabandeh, F., \& Yekta, R. R. (2019). Comparing and contrasting the interactional performance of teachers and students in traditional and virtual classrooms of advanced writing course in distance Education University. Turkish Online Journal of Distance Education, 20(4), 135-148. https://doi.org/10.17718/TOJDE.640552n

Brito, M., Medeiros, F., \& Bezerra, E. P. (2019). An infographics-based tool for monitoring dropout risk on distance learning in higher education. 2019 18th International Conference on Information Technology Based Higher Education and Training, ITHET 2019. https://doi.org/10.1109/ITHET46829.2019.8937361n

Del Prete, A., Almenara Cabero, J., \& Halal Orfali, C. (2018). Motivos inhibidores del uso del Moodle en docentes de educacion superior Motives inhibitors of the use of Moodle in higher education teachers. Campus Virtuales: Revista Científica Iberoamericana de Tecnología Educativa, 7, 69-80. https://hdl.handle.net/11441/81058n

Domínguez, D., Alvarez, J. F., \& Gil-Jaurena, I. (2016). Analítica del aprendizaje y Big Data: heurísticas y marcos $\begin{array}{llll}\text { interpretativos. } & \text { Dilemata, 87-103. }\end{array}$ https://www.dilemata.net/revista/index.php/dilemata/article/view/412000042n

Esnaola-Arribillaga, I., \& Bezanilla, M. J. (2020). Levels of Moodle use to support university face-to-face teaching. Revista Iberoamericana de Tecnologias Del Aprendizaje, 15(3), 129-137. https://doi.org/10.1109/RITA.2020.3008376n

Ez-Zaouia, M., \& Lavoue, E. (2017). EMODA: A tutor oriented multimodal and contextual emotional dashboard. ACM International Conference Proceeding Series, 429-438. https://doi.org/10.1145/3027385.3027434n

Fillbrunn, A., Dietz, C., Pfeuffer, J., Rahn, R., Landrum, G. A., \& Berthold, M. R. (2017). KNIME for deproducible cross-domain analysis of life science data. Journal of Biotechnology, 261, 149-156. https://doi.org/10.1016/j.jbiotec.2017.07.028n

Florian-Gaviria, B., Glahn, C., \& Fabregat Gesa, R. (2013). A software suite for efficient use of the European qualifications framework in online and blended courses. IEEE Transactions on Learning Technologies, 6(3), 283-296. https://doi.org/10.1109/TLT.2013.18n

Hibbi, F. Z., Abdoun, O., \& Haimoudi, E. K. (2019). Exploration of Analytical Mechanisms in the Feedback model. Procedia Computer Science, 148, 201-207. https://doi.org/10.1016/j.procs.2019.01.037n

Jara, A., Genound, D., \& Bocchi, Y. (2014). Big data for smart cities with KNIME a real experience in the SmartSantander testbed Antonio. Volume45, Issue8 Special Issue: Intelligent Technologies and Applications for Big Data Analytics, 39(7), 701-736. https://doi.org/10.1002/spe.2274n

Kew, S. N., \& Tasir, Z. (2021). Learning analytics in online learning environment: a systematic review on the focuses and the types of student-related analytics data. Technology, Knowledge and Learning, 0123456789. https://doi.org/10.1007/s10758-021-09541-2n

Kresimir, R., Marijana, B. G., \& Vlado, M. (2014). Development of the intelligent system for the use of university information system. Procedia Engineering, 69, 402-409. https://doi.org/10.1016/i.proeng.2014.03.005n 
Ninasivincha-Apfata, J.E., Quispe-Figueroa, R.C., Valderrama-Solis, M.A. \& Maraza-Quispe, B.M. (2021). Dashboard proposal implemented according to an analysis developed on the KNIME platform. World Journal on Educational Technology: Current Issues. 13(4), 816-837. https://doi.org/10.18844/wjet.v13i4.6267

Liu, D., Richards, D., Froissard, C., \& Atif, A. (2015). Validating the Effectiveness of the Moodle Engagement Analytics Plugin to Predict Student Academic Performance. 2015 Americas Conference on Information Systems, AMCIS 2015, December. https://www.semanticscholar.org/paper/Validating-the-Effectivenessof-the-Moodle-Plugin-Atif-Froissard/c456d1455bf8941b8625b234dda84e5808bbc5dfn

Liu, D. Y. T., Atif, A., Froissard, J. C., \& Richards, D. (2019). An enhanced learning analytics plugin for Moodle: Student engagement and personalised intervention. ASCILITE 2015 - Australasian Society for Computers in Learning and Tertiary Education, Conference Proceedings, 180-189. https://www.semanticscholar.org/paper/An-enhanced-learning-analytics-plugin-for-Moodle\%3A-LiuFroissard/9d18ece88e54f9e7ef17d90e08e16dfe5047c44cn

Mahou-Lago, X.-M., Lopez Viso, M., \& Varela-Alvarez, E. J. (2020). Master's degrees in the Spanish university system: assessing the virtualization of online courses. Aula de Encuentro, 22(1), 34-56. https://doi.org/10.17561/ae.v22n1.2n

Marek, M. W., Chew, C. S., \& Wu, W. C. V. (2021). Teacher experiences in converting classes to distance learning in the covid-19 pandemic. International Journal of Distance Education Technologies, 19(1), 89-109. https://doi.org/10.4018/IJDET.20210101.0a3n

Mejia, C., Florian, B., Vatrapu, R., Bull, S., Gomez, S., \& Fabregat, R. (2017). A novel web-based approach for visualization and inspection of reading difficulties on university students. IEEE Transactions on Learning Technologies, 10(1), 53-67. https://doi.org/10.1109/TLT.2016.2626292n

Michaeli, S., Kroparo, D., \& Hershkovitz, A. (2020). Teachers' use of education dashboards and professional growth. International Review of Research in Open and Distance Learning, 21(4), 61-78. https://doi.org/10.19173/IRRODL.V21/4.4663n

Mwalumbwe, I., \& Mtebe, J. S. (2017). Using learning analytics to predict students' performance in moodle learning management system: A case of Mbeya University of science and technology. Electronic Journal of Information Systems in Developing Countries, 79(1), 1-13. https://doi.org/10.1002/j.16814835.2017.tb00577.xn

O’Doherty, D., Dromey, M., Lougheed, J., Hannigan, A., Last, J., \& McGrath, D. (2018). Barriers and solutions to online learning in medical education - An integrative review. El Dia Medico, 20(22), 832-834. https://doi.org/https://doi.org/10.1186/s12909-018-1240-0n

Ordonez-almeida, K., Guana-moya, J., Garcia-herrera, D., Naranjo-villota, D., Bonilla-morales, C., \& Cajamarcayunga, J. (2020). Analisis del uso de los recursos en la plataforma virtual de ensenanza aprendizaje. Revista Iberica de Sistemas e Tecnologias de Informacao, 2 (September 2018), 126-137. https://www.proquest.com/openview/5d92effec869242e21f7c8d9376e034d/1?pqorigsite $=$ gscholar $\& \mathrm{cbl}=1006393 \mathrm{n}$

Prokofieva, M. (2021). Using dashboards and data visualizations in teaching accounting. Education and Information Technologies, 26(5), 5667-5683. https://doi.org/10.1007/s10639-021-10525-zn

Ramos-Soto, A., Lama, M., Vazquez-Barreiros, B., Bugarin, A., Mucientes, M., \& Barro, S. (2015). Towards textual reporting in learning analytics dashboards. Proceedings - IEEE 15th International Conference on Advanced Learning Technologies: Advanced Technologies for Supporting Open Access to Formal and Informal Learning, ICALT 2015, 260-264. https://doi.org/10.1109/ICALT.2015.96n

Ribeiro, L. R., \& Montanaro, P. R. (2017). A gamificacao gamificada: desenvolvimento de um curso para capacitacao de docentes. Revista on Line de Politica e Gestao Educacional, 21(esp3), 1626-1637. https://doi.org/10.22633/rpge.v21.n.esp3.2017.10074n

Robalino, A. D. (2017). Metodologia para el diseno de Dashboards orientado hacia el registro de evidencias en el proceso de evaluaciones institucionales. 88. https://reunir.unir.net/handle/123456789/6171n 

according to an analysis developed on the KNIME platform. World Journal on Educational Technology: Current Issues. 13(4), 816-837. https://doi.org/10.18844/wjet.v13i4.6267

Saiz-Manzanares, M. C., Marticorena-Sanchez, R., \& Garcia-Osorio, C. I. (2020). Monitoring students at the university: Design and application of a Moodle plugin. Applied Sciences (Switzerland), 10(10). https://doi.org/10.3390/app10103469n

Santoso, H. B., Batuparan, A. K., Isal, R. Y. K., \& Goodridge, W. H. (2018). The development of a learning dashboard for lecturers: A case study on a student-centered e-learning environment. Journal of Educators Online, 15(1). https://doi.org/10.9743/JEO.2018.1.1n

Sharma, S., \& Bumb, A. (2021). The challenges faced in technology-driven classes during covid-19. International Journal of Distance Education Technologies, 19(1), 66-88. https://doi.org/10.4018/IJDET.20210101.oa2n

Tlili, A., Essalmi, F., Jemni, M., Chang, M., \& Kinshuk. (2018). iMoodle: An intelligent Moodle based on learning analytics. Lecture Notes in Computer Science (Including Subseries Lecture Notes in Artificial Intelligence and Lecture Notes in Bioinformatics), 10858 LNCS (August), 476-479. https://doi.org/10.1007/978-3-319$\underline{91464-0 \mathrm{n}}$

Van Alphen, E., \& Bakker, S. (2016). Lernanto: Using an ambient display during differentiated instruction. Conference on Human Factors in Computing Systems - Proceedings, 07-12-May-2016, 2334-2340. https://doi.org/10.1145/2851581.2892524n

Verbert, K., Ochoa, X., De Croon, R., Dourado, R. A., \& De Laet, T. (2020). Learning analytics dashboards: The past, the present and the future. ACM International Conference Proceeding Series, 35-40. https://doi.org/10.1145/3375462.3375504n

Zacarias, E., de Almeida, L. R., Prettz, J. B., da Costa, J. P. C. L., de Freitas, E. P., Canedo, E. D., \& de Sousa, R. T. (2016). Optimizing the access records of students in the moodle virtual learning environment database. IFAC-PapersOnLine, 49(30), 98-101. https://doi.org/10.1016/j.ifacol.2016.11.135n

Zimmerman, C., Stein, M.-K., Hardt, D., Danielsen, C., \& Vatrapu K. R. (2016). EmotionVis: Designing an emotion text inference tool for visual analytics. Lecture Notes in Computer Science (Including Subseries Lecture Notes in Artificial Intelligence and Lecture Notes in Bioinformatics), 9661 LNCS (May), 238-244. https://doi.org/10.1007/978-3-319-39294-3 22n 